\title{
Pengaruh Kompensasi dan Kompleksitas Tugas terhadap Kepuasan Kerja dengan Motivasi Kerja sebagai Variabel Intervening pada PT. Bank Sumut Cabang Sukaramai Medan
}

\author{
Julia Raisa Putri \\ juliaraisaputri18@gmail.com \\ Universitas Harapan Medan
}

\author{
Saskia Yusuf \\ saskiayusuf@gmail.com \\ Universitas Harapan Medan \\ Sunaryo \\ sunaryo.dosen@gmail.com \\ Universitas Harapan Medan
}

\begin{abstract}
This study aims to determine the effect of compensation and task complexity on job satisfaction through work motivation directly or indirectly at PT. Bank Sumut Branch of Sukaramai Medan. Path analysis research design is used as an analytical tool to determine the direction of the variables studied and to justify how significant the influence of the dependent independent variable is directly and indirectly through the mediating variable. In this study, the associative method is used with a quantitative approach. In this study, the entire population that became the sample was 103 employees at PT. Bank Sumut, Sukaramai Branch Medan. The results showed that compensation had a significant effect on work motivation, task complexity had no and no significant effect on work motivation, compensation had a significant effect on job satisfaction, complexity. Duties have no and insignificant effect on job satisfaction, work motivation has a significant effect on job satisfaction, compensation has no significant effect on work motivation through job satisfaction, task complexity has no effect on job motivation through job satisfaction.
\end{abstract}

Keywords : compensation, job satisfaction, task complexity, work motivation.

\section{Pendahuluan}

Dalam menjalankan suatu bisnis perusahaan membutuhkan berbagai macam sumber daya, seperti modal dan material. Perusahaan juga membutuhkan sumber daya manusia yaitu para karyawan. Sumber daya manusia merupakan salah satu faktor terpenting dalam suatu organisasi atau perusahaan, disamping faktor lain seperti aktiva dan modal. Oleh karena itu sumber daya manusia harus dikelola dengan baik untuk meningkatkan efektifitas dan efisiensi organisasi, sebagai salah satu fungsi dalam perusahaan yang dikenal dengan manajemen sumber daya manusia.

Kompensasi pada PT. Bank Sumut sangat penting bagi karyawan itu sendiri sebagai individu, karena besarnya kompensasi merupakan cerminan atau ukuran nilai pekerjaan karyawan itu sendiri. Sebaliknya, besar kecilnya kompensasi dapat mempengaruhi kepuasan kerja. Apabila kompensasi diberikan secara tepat dan benar para karyawan akan memperoleh kepuasan kerja dan termotivasi untuk mencapai tujuan-tujuan organisasi. Akan tetapi bila kompensasi itu diberikan tidak memadai atau kurang tepat maka akan terjadi penurunan kepuasan kerja pada karyawan. 


\section{Kajian Pustaka}

\subsection{Kepuasan Kerja}

Kepuasan kerja menurut Ahmadi \& Hermawan (2013) adalah keadaan emosional yang menyenangkan atau tidak menyenangkan terhadap pekerjaan, kepuasan kerja mencerminkan perasaan seeorang terhadap terhadap pekerjaannya. Ada beberapa indikator kepuasan kerja pada setiap dimensinya, berikut penjelasannya :

a. Pekerjaan yang dapat memberikan tantangan, kenyamanan, dan pekerjaan yang menarik.

b. Kesesuaian pendapatan dengan pekerjaan yang dilakukan.

c. Kesempatan promosi yang diberikan perusahaan setelah apa yang dikerjakan oleh karyawan.

d. Pengarahan dan pengendalian yang diberikan atasan kepada karyawan.

e. Hubungan dengan rekan kerja dan pimpinan sangat baik.

f. Fasilitas yang diberikan perusahaan sudah cukup membantu untuk

g. menyelesaikan tugas yang diberikan.

\subsection{Motivasi Kerja}

Menurut Widodo (2015), motivasi adalah kekuatan yang ada dalam seseorang, yang mendorong perilakunya untuk melakukan tindakan. Besarnya intensitas kekuatan dari dalam diri seseorang untuk melakukan suatu tugas atau mencapai sasaran memperlihatkan sejauh mana tingkat motivasinya. Menurut Mangkunegara (2011), motivasi terdiri dari tiga dorongan kebutuhan, yaitu:

a. Kebutuhan akan prestasi (Needs of Achievment), diukur dengan menggunakan tiga indikator, yaitu:

1) Kebutuhan untuk mengembangkan kreativitas.

2) Kebutuhan untuk menggerakan kemampuan.

3) Kebutuhan untuk bekerja secara efektif dan efisien.

b. Kebutuhan untuk menjalin hubungan personal (Needs of Affiliantion), diukur dengan menggunakan tiga indikator, yaitu:

1) Kebutuhan untuk diterima.

2) Kebutuhan untuk menjalin hubungan baik antar pegawai.

3) Kebutuhan untuk ikut serta dan bekerja sama.

c. Kebutuhan untuk berkuasa dan berpengaruh pada orang lain (Needs of Power), diukur dengan menggunakan tiga indikator, yaitu :

1) Kebutuhan untuk memberikan pengaruh dan aturan dalam lingkungan kerja.

2) Kebutuhan untuk mengembangkan kekuasaan dan tanggung jawab.

3) Kebutuhan untuk memimpin dan bersaing.

\subsection{Kompensasi}

Pengertian kompensasi menurut Sastrohadiwiryo dalam Yuniarsih \& Suwatno (2016) adalah imbalan saja atau balas jasa yang diberikan perusahaan kepada para tenaga kerja,karena para tenaga kerja tersebut telah memberikan sumbangan tenaga dan fikiran meraka demi kemajuan perusahaan guna mencapai tujuan yang ditetapkan. Menurut Simamora (2004), indikator untuk mengukur kompensasi karyawan diantaranya sebagai berikut:

a. Upah dan gaji, Upah adalah basis bayaran yang seringkali digunakan bagi para pekerja produksi dan pemeliharaan. Upah pada umumnya berhubungan dengan tarif gaji per jam dan gaji biasanya berlaku untuk tarif bayaran tahunan, bulanan atau mingguan.

b. Insentif, Pengertian Insentif adalah tambahan kompensasi di atas atau di luar gaji atau upah yang diberikan oleh perusahaan.

c. Tunjangan, Pengertian Tunjangan adalah asuransi kesehatan dan jiwa, program pensiun, liburan yang ditanggung perusahaan, dan tunjangan lainnya yang berkaitan dengan hubungan kepegawaian. 
d. Fasilitas, Pengertian Fasilitas adalah pada umumnya berhubungan dengan kenikmatan seperti mobil perusahaan, akses ke pesawat perusahaan, tempat parkir khusus dan kenikmatan (baca: perlakuan khusus) yang diperoleh karyawan.

\subsection{Kompleksitas Tugas}

Menurut Kurniawan, dkk (2016), kompleksitas tugas merupakan salah satu variabel yang secara konsisten berhubungan dengan kepuasan kerja. Jika kompleksitas tugas audit dihubungkan dengan kepuasan kerja audi-tor, maka tugas audit harus dibuat menarik. Menurut Boynton (2010), terdapat empat indikator penyusunan kompleksitas tugas, yaitu:

a. Tingkat sulitnya tugas, tingkat sulitnya tugas selalu dikaitkan dengan banyaknya informasi tentang tugas tersebut.

b. Struktur tugas, struktur tugas terkait dengan kejelasan informasi (information clarity).

c. Banyaknya informasi yang tidak relevan dalam artian informasi tersebut tidak konsisten dengan kejadian yang akan diprediksikan.

d. Adanya ambiguitas yang tinggi yaitu beragamnya outcome (hasil) yang diterapkan oleh klien dari kegiatan pengauditan.

\subsection{Kerangka Konseptual}

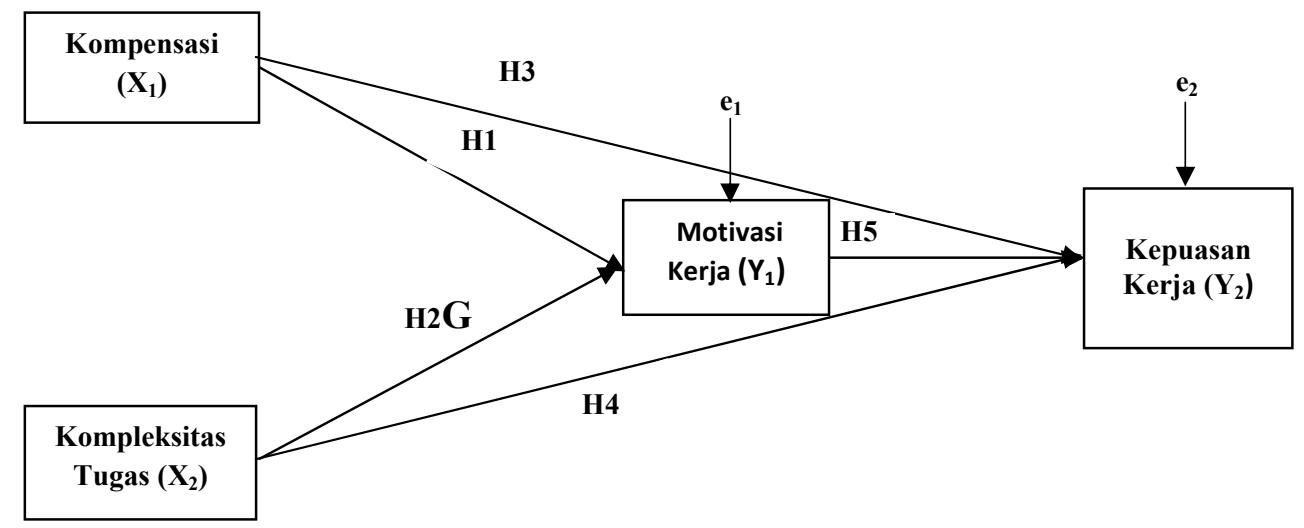

Gambar 2.1 Kerangka Konseptual

\subsection{Hipotesis Penelitian}

Berdasarkan Kerangka Konseptual maka didapat hipotesis sebagai berikut :

a. $\mathrm{H}_{1}$ : Kompensasi berpengaruh signifikan terhadap Motivasi Kerja pada PT. Bank Sumut Cabang Sukaramai Medan.

b. $\mathrm{H}_{2}$ : Kompleksitas Tugas berpengaruh signifikan terhadap Motivasi Kerja pada PT. Bank Sumut Cabang Sukaramai Medan.

c. $\mathrm{H}_{3}$ : Kompensasi berpengaruh signifikan terhadap Kepuasan Kerja pada PT. Bank Sumut Cabang Sukaramai Medan.

d. $\mathrm{H}_{4}$ : Kompleksitas Tugas berpengaruh signifikan terhadap Kepuasan Kerja Pada PT. Bank Sumut Cabang Sukaramai Medan.

e. $\mathrm{H}_{5}$ : Motivasi Kerja berpengaruh terhadap Kepuasan Kerja pada PT. Bank Sumut Cabang Sukaramai Medan.

f. $\mathrm{H}_{6}$ : Kompensasi berpengaruh terhadap Kepuasan Kerja melalui Motivasi Kerja pada PT. Bank Sumut Cabang Sukaramai Medan.

g. $\mathrm{H}_{7}$ : Kompleksitas Tugas berpengaruh signifikan terhadap Motivasi melalui Kepuasan Kerja pada PT. Bank Sumut Cabang Sukaramai Medan. 


\section{Metode Penelitian}

Jenis penelitian ini adalah penelitian asosiatif. Populasi dalam penelitian ini berjumlah 103 karyawan dan sampel ini menggunakan Teknik penarikan sampel pada penelitian ini dengan menggunakan sampel jenuh (bored sampling) dimana semua bagian populasi menjadi sampel.

\section{Analisis dan Pembahasan}

4.1. Analisis Data

4.1.1. Karakteristik Reponden

Tabel 1 Karakteristik Responden

\begin{tabular}{|c|c|c|c|}
\hline Variabel Demografi & Keterangan & Frekuensi & Persentase (\%) \\
\hline \multirow{3}{*}{ Jenis Kelamin } & Laki - Laki & 41 & $39,81 \%$ \\
\cline { 2 - 4 } & Perempuan & 62 & $60,19 \%$ \\
\hline \multirow{3}{*}{ Usia } & $>25$ tahun & 14 & $13,59 \%$ \\
\cline { 2 - 4 } & $>26-20$ tahun & 46 & $44,66 \%$ \\
\cline { 2 - 4 } & $>31-40$ tahun & 34 & $33,01 \%$ \\
\cline { 2 - 4 } & $>41-50$ tahun & 9 & $8,74 \%$ \\
\hline \multirow{3}{*}{ Pendidikan } & SMA & 20 & $32,42 \%$ \\
\cline { 2 - 4 } & DIPLOMA & 33 & $33,98 \%$ \\
\cline { 2 - 4 } & S1 & 35 & $14,56 \%$ \\
\cline { 2 - 4 } & S2 & 15 & \\
\hline
\end{tabular}

Sumber : Data Primer Diolah 2020

\subsubsection{Uji Asumsi Klasik}

a. Uji Normalitas

Tabel 2 Hasil Uji Normalitas

\begin{tabular}{|c|c|c|c|}
\hline \multicolumn{4}{|c|}{ Normalitas } \\
\hline & g(2-tailed) & Sig & Keterangan \\
\hline Sub I & 0,062 & 005 & Normol \\
\hline Sub II & 0,132 & 0,05 & Normal \\
\hline
\end{tabular}

Sumber : Data Primer Diolah 2020

Tabel 2 menunjukkan bahwa nilai Asymp. Sig lebih besar dari 0,05, sehingga dapat disimpulkan bahwa data telah berdistribusi secara normal.

b. Uji Multikolinearitas

Tabel 3 Hasil Uji Multikolinearitas

\begin{tabular}{|c|c|c|c|c|}
\hline \multirow{3}{*}{ Sub I } & Model & Tolerance & VIF & \multirow{2}{*}{ Keterangan } \\
\cline { 2 - 4 } & $\mathrm{X} 1$ & 1,000 & 1,000 & \multirow{3}{*}{ Tidak ada } \\
\cline { 2 - 4 } Sub II & $\mathrm{X} 2$ & 1,000 & 1,000 & 1,459 \\
\cline { 2 - 4 } & $\mathrm{X} 1$ & 0,685 & 1,033 & \\
\cline { 2 - 4 } & $\mathrm{X} 2$ & 0,968 & 1,420 & \\
\cline { 2 - 4 } & $\mathrm{Y} 1$ & 0,704 & \\
\hline
\end{tabular}

Sumber : Data Primer Diolah 2020

Tabel 3 menunjukkan bahwa nilai korelasi variabel bebas terhadap variabel terkaitnya nilai tersebut di tunjukkan dengan nilai Tolerance dan VIF. Nilai VIF dari setiap model dalam penelitian lebih kecil atau dibawah 10 ( VIF < 10), berarti tidak terkena multikolinearitas antara variabel independen. Dan nilai Tolerance dari setiap model dalam penelitian lebih besar dai 0,1 ini berarti tidak terdapat multikolinearitas antar variabel. 
c. Uji Heteroskesdastisitas

Tabel 4 Hasil Uji Heteroskedastisitas

\begin{tabular}{|c|c|c|}
\hline \multicolumn{2}{|c|}{ Sig } & \multirow{2}{*}{ Keterangan } \\
\hline \multirow{2}{*}{ Sub I } & 0,973 & \multirow{2}{*}{ Tidak terjadi } \\
\cline { 2 - 2 } & 0,014 & Heteroskesdastisitas \\
\cline { 2 - 2 } Sub II & 0,111 & \\
\cline { 2 - 2 } & 0,454 & \\
\cline { 2 - 2 } & 0,621 & \\
\hline
\end{tabular}

Sumber : Data Primer Diolah 2020

Tabel 4 menunjukkan bahwa hasil uji heteroskesdastisitas tidak mengandung heteroskesdastisitas karena nilai signifikan lebih besar dari 0,05, artinya tidak ada korelasi antara besarnya data dengan residual.

\subsubsection{Koefisien Determinasi $\left(\mathrm{R}^{2}\right)$}

Tabel 5 Hasil Uji Koefisien Determinasi $\left(R^{2}\right)$

\begin{tabular}{|c|c|c|c|c|}
\hline \multicolumn{2}{|c|}{ Variabel Independen } & R (R²) & R Square & $\begin{array}{c}\text { Adjusted R } \\
\text { Square }\end{array}$ \\
\hline Sub I & $\mathrm{X} 2 . \mathrm{X} 1$ & 0,543 & 0,295 & 0,281 \\
\hline Sub II & $\mathrm{Y} 1, \mathrm{X} 2, \mathrm{X} 1$ & 0,673 & 0,453 & 0,437 \\
\hline
\end{tabular}

\section{Sumber : Data Primer Diolah 2020}

Berdasarkan tabel 5 diperoleh koefisien determinasi $\left(\mathrm{R}^{2}\right)$ sebesar 0,295 dan 0,453 artinya pengaruh $X_{1}$ terhadap $X_{2}$ sebesar $29,5 \%$, sedangkan untuk variabel $Y 1, X 2, X 1$ sebesar $45,3 \%$ sedangkan sisanya dipengaruhi oleh variabel lainnya.

\subsubsection{Uji Model Sub I,II ( Uji F)}

Tabel 6 Hasil Uji Model Sub 1 ( Uji F )

\begin{tabular}{|c|c|c|c|c|}
\hline \multicolumn{2}{|c|}{ Variabel Independen } & $\begin{array}{c}\text { Variabel } \\
\text { Dependen }\end{array}$ & F & Sig \\
\hline Sub I & X1 & Y1 & 20,958 & 0,000 \\
\hline Sub II & X2 & Y2 & 27,340 & 0,000 \\
\hline
\end{tabular}

Sumber : Data Primer Diolah 2020

Berdasarkan tabel 6 diketahui nilai sig $<0,05$ dan $F_{\text {hitung }}>F_{\text {tabel }}(20,958>3,09)$ maka dapat disimpulkan bahwa model menunjukkan fit.

\subsubsection{Analisis Persamaan Model Sub I,II}

Tabel 7 Hasil Uji Persamaan Model Regresi Sub I,II

\begin{tabular}{|c|c|c|c|c|c|c|}
\hline \multicolumn{7}{|c|}{ Coefficients $^{\mathbf{a}}$} \\
\hline \multirow{2}{*}{\multicolumn{2}{|c|}{ Model }} & \multicolumn{2}{|c|}{$\begin{array}{l}\text { Unstandardized } \\
\text { Coefficients }\end{array}$} & \multirow{2}{*}{$\begin{array}{c}\begin{array}{c}\text { Standardized } \\
\text { Coefficients }\end{array} \\
\text { Beta }\end{array}$} & \multirow[t]{2}{*}{$\mathrm{T}$} & \multirow[t]{2}{*}{ Sig. } \\
\hline & & B & Std. Error & & & \\
\hline \multirow[t]{3}{*}{1} & (Constant) & 8,653 & 3,626 & & 2,387 & ,019 \\
\hline & $\mathrm{x} 1$ &, 514 &, 080 & ,543 & 6,466 & 000 \\
\hline & $\mathrm{x} 2$ &,- 030 & ,091 &,- 027 &,- 326 & ,745 \\
\hline \multirow[t]{4}{*}{2} & (Constant) & $-1,882$ & 5,113 & &,- 368 & ,714 \\
\hline & $\mathrm{X} 1$ & ,803 & ,175 & ,420 & 4,579 & 000 \\
\hline & $\mathrm{X} 2$ & ,113 & ,153 &, 049 & ,741 & , 461 \\
\hline & $\mathrm{y} 1$ & ,868 & ,194 & ,407 & 4,482 & 000 \\
\hline
\end{tabular}

Sumber : Data Primer Diolah 2020

$$
Y_{1}=P Y_{1} X_{1}+P Y_{1} X_{2}+e_{1}, Y_{2}=P Y_{2} X_{1}+P Y_{2} X_{2}+P Y_{2} X_{1}+e_{2}
$$




\subsubsection{Uji t ( Parsial)}

Tabel 8 Hasil Uji t ( Parsial) Sub I,II

\begin{tabular}{|c|c|c|c|}
\hline & Hipotesis & Nilai & sig \\
\hline \multirow{3}{*}{ Sub I } & $\mathrm{X} 1 . \mathrm{Y} 1$ & 0,80 & 0,000 \\
\cline { 2 - 4 } & $\mathrm{X} 2 . \mathrm{Y} 1$ & 0,091 & 0,745 \\
\hline \multirow{3}{*}{ Sub II } & $\mathrm{X} 1 . \mathrm{Y} 2$ & 0,175 & 0,000 \\
\cline { 2 - 4 } & $\mathrm{X} 2 . \mathrm{Y} 2$ & 0,153 & 0,461 \\
\cline { 2 - 4 } & $\mathrm{Y} 1 . \mathrm{Y} 2$ & 0,194 & 0,000 \\
\hline
\end{tabular}

Sumber : Data Primer Diolah 2020

Berdasarkan tabel 8 dapat diketahui nilai signifikansi standardized Kompensasi lebih besar dari 0,05 $(0,000<0,05)$. Dan nilai signifikansi standardized Kompensasi lebih kecil dari 0,05 $(0,000<0,05)$. Dan nilai $t_{\text {hitung }}>t_{\text {tabel }}(6,466>1,660)$. nilai signifikansi standardized Kompleksitas Tugas lebih besar dari 0,05 $(0,745>0,05)$. Dan nilai $t_{\text {hitung }}>t_{\text {tabel }}(-0,326<1,660)$. nilai $t_{\text {hitung }}>$ $t_{\text {tabel }}(4,579>1,98)$. nilai signifikansi standardized Kompleksitas Tugas lebih kecil dari 0,05 $(0,461>0,05)$. Dan nilai $t_{\text {hitung }}>t_{\text {tabel }}(0,741<1,660)$. nilai signifikansi standardized Motivasi Kerja lebih besar dari 0,05 $(0,000<0,05)$. Dan nilai $t_{\text {hitung }}>t_{\text {tabel }}(4.482>1,660)$.

\subsubsection{Pengaruh Langsung}

\begin{tabular}{|c|c|c|}
\hline \multicolumn{3}{|c|}{ Tabel 9 Pengaruh Langsung } \\
\hline Hipotesis & $\begin{array}{c}\text { Standardized Coefficients } \\
\text { Beta }\end{array}$ & Sig \\
\hline $\mathrm{H} 1: \mathrm{X} 1 \rightarrow \mathrm{Y} 1$ & 0,543 & 0,000 \\
\hline $\mathrm{H} 2: \mathrm{X} 2 \rightarrow \mathrm{Y} 1$ & $-0,027$ & 0,745 \\
\hline $\mathrm{H} 3: \mathrm{X} 1 \rightarrow \mathrm{Y} 2$ & 0,420 & 0,000 \\
\hline $\mathrm{H} 4: \mathrm{X} 2 \rightarrow \mathrm{Y} 2$ & 0,049 & 0,461 \\
\hline $\mathrm{H} 5: \mathrm{Y} 1 \rightarrow \mathrm{Y} 2$ & 0,407 & 0,000 \\
\hline
\end{tabular}

Sumber : Data Primer Diolah 2020

Berdasarkan tabel 4.54 di atas dapat dilihat bahwa $\mathrm{H}_{1}, \mathrm{H}_{3}$ dan $\mathrm{H}_{5}$ memiliki nilai sig $<0,005$, sehingga dapat disimpulkan bahwa secara langsung terdapat pengaruh yang signifikan antar variabel. Pada $\mathrm{H}_{2}$ dan $\mathrm{H}_{4}$ nilai sig > 0,005 sehingga dapat disimpulkan bahwa secara langsung tidak ada pengaruh yang signifikan antar variabel.

\subsubsection{Pengaruh Tidak Langsung}

Tabel 10 Pengaruh Tidak Langsung

\begin{tabular}{|l|l|}
\hline \multicolumn{2}{|c|}{ Pengaruh Tidak Langsung } \\
\hline Hubungan & $\mathrm{p}$-value \\
\hline $\mathrm{H} 6: \mathrm{X} 1 \rightarrow \mathrm{Y} 1 \rightarrow \mathrm{Y} 2$ & 0,228 \\
\hline $\mathrm{H} 7: \mathrm{X} 2 \rightarrow \mathrm{Y} 1 \rightarrow \mathrm{Y} 2$ & 1,323 \\
\hline
\end{tabular}

Sumber : Data Primer Diolah 2020

Berdasarkan tabel 10 di atas dapat dilihat bahwa H6 dan H7 memiliki nilai p-value > 0,005 , sehingga dapat disimpulkan bahwa secara tidak langsung terdapat pengaruh mediasi pada $\mathrm{X}_{1}$ dan $\mathrm{X}_{2}$ terhadap $\mathrm{Y}_{2}$. 


\subsection{Pembahasan}

a. Hasil penelitian ini diketahui bahwa Kompensasi berpengaruh signifikan terhadap Motivasi Kerja pada PT. Bank Sumut Cabang Sukaramai Medan. Hasil penelitian ini sejalan dengan hasil penelitian yang dilakukan oleh Atika \& Prasetio (2015) yang menyatakan bahwa Kompensasi berpengaruh terhadap Motivasi maupun juga terhadap Kinerja Karyawan. Sehingga dapat disimpulkan bahwa Hipotesis 1 diterima.

b. Hasil penelitian ini diketahui bahwa Kompleksitas Tugas tidak berpengaruh dan tidak signifikan terhadap Motivasi Kerja pada PT. Bank Sumut Cabang Sukaramai Medan. Hasil penelitian ini tidak sejalan dengan hasil penelitian yang dilakukan oleh Zulkarnaen \& Kusmayadi (2013), yang menyatakan bahwa Kompleksitas Tugas berpengaruh negatif dan signifikan terhadap Motivasi Kerja. Sehingga dapat disimpulkan bahwa Hipotesis 2 ditolak.

c. Hasil penelitian ini diketahui bahwa Kompensasi berpengaruh positif dan signifikan terhadap Kepuasan Kerja pada PT. Bank Sumut Cabang Sukaramai Medan. Hasil penelitian ini sejalan dengan hasil penelitian yang dilakukan oleh Wangsa (2016) dan penelitian yang dilakukan oleh Kusuma, dkk (2015) yang menyatakan bahwa Kompensasi berpengaruh signifikan terhadap Kepuasan Kerja. Sehingga dapat disimpulkan Hipotesis 3 diterima.

d. Hasil penelitian ini diketahui bahwa Kompleksitas Tugas tidak berpengaruh dan tidak signifikan terhadap Kepuasan Kerja pada PT. Bank Sumut Cabang Sukaramai Medan. Hasil penelitian ini tidak sejalan dengan hasil penelitian yang dilakukan oleh (Paulus, Hasan, \& Mezal, 2015) yang menyatakan bahwa Kompleksitas Tugas berpengaruh terhadap Kepuasan Kerja. Bahwa dapat disimpulkan hipotesis 4 ditolak.

e. Hasil penelitian ini diketahui bahwa Motivasi Kerja berpengaruh positif dan signifikan terhadap Kepuasan Kerja pada PT. Bank Sumut Cabang Sukaramai Medan. Hasil penelitian ini sejalan dengan hasil penelitian yang dilakukan oleh Kartika dan Kaihatu (2010) yang menyatakan bahwa Motivasi Kerja berpengaruh positif dan signifikan terhadap Kepuasan Kerja. Bahwa dapat disimpulkan Hipotesis 5 diterima.

f. Hasil penelitian ini diketahui bahwa Kompensasi berpengaruh tidak signifikan terhadap Motivasi Kerja dimediasi oleh Kepuasan Kerja pada PT. Bank Sumut Cabang Sukaramai Medan. Hasil penelitian ini sejalan dengan hasil penelitian yang dilakukan oleh Sari \& Ardana (2016) dan penelitian yang dilakukan oleh Nurcahyani \& Adnyani (2016) yang menempatkan Kepuasan Kerja sebagai variabel mediasi terhadap Kinerja Karyawan. Hasil penelitian ini juga mendukung Hasil penelitian Atika \& Prasetio (2015) yang menyatakan Kompensasi berpengaruh terhadap Motivasi Kerja sehingga dapat disimpulkan bahwa hipotesis 6 diterima.

g. Hasil penelitian ini diketahui bahwa Kompleksitas Tugas berpengaruh tidak signifikan terhadap motivasi kerja melalui Motivasi Kerja pada PT. Bank Sumut Cabang Sukaramai Medan. Hasil penelitian ini tidak sejalan dengan hasil penelitian yang dilakukan oleh Prassetiawan \& Triyani (2019) yang menyatakan Kepuasan Kerja bukan sebagai variabel mediasi terhadap Kinerja Karyawan. Sehingga dapat disimpulkan hipotesis 7 diterima.

\section{Kesimpulan dan Rekomendasi}

\subsection{Kesimpulan}

a. Kompensasi berpengaruh signifikan terhadap Motivasi Kerja pada PT. Bank Sumut Cabang Sukaramai Medan.

b. Kompleksitas Tugas tidak berpengaruh dan tidak signifikan terhadap Motivasi Kerja pada PT. Bank Sumut Cabang Sukaramai Medan.

c. Kompensasi berpengaruh signifikan terhadap Kepuasan Kerja pada PT. Bank Sumut Cabang Sukaramai Medan.

d. Kompleksitas Tugas tidak berpengaruh dan tidak signifikan terhadap Kepuasan Kerja pada PT. Bank Sumut Cabang Sukaramai Medan.

e. Motivasi Kerja berpengaruh signifikan terhadap Kepuasan Kerja pada PT. Bank Sumut Cabang Sukaramai Medan. 
f. Kompensasi berpengaruh dan tidak signifikan terhadap Motivasi Kerja melalui Kepuasan Kerja pada PT. Bank Sumut Cabang Sukaramai Medan.

g. Kompleksitas Tugas berpengaruh dan signifikan terhadap Motivasi Kerja melalui Kepuasan Kerja pada PT. Bank Sumut Cabang Sukaramai Medan.

\subsection{Rekomendasi}

a. Hasil penelitian mengenai kompensasi terhadap motivasi kerja di PT. Bank Sumut Cabang Sukaramai Medan mempunyai hasil yang baik, sehingga disarankan agar divisi yang mengatur kompensasi karyawan selalu memberi motivasi agar karyawan memiliki semangat kerja yang tinggi sehingga kompensasi yang diberikan sesuai dengan hasil dari pekerjaan yang telah dilakukan oleh karyawan.

b. Hasil penelitian mengenai kompensasi terhadap kepuasan kerja di PT. Bank Sumut Cabang Sukaramai Medan mempunyai hasil yang relatif baik, sehingga disarankan agar pimpinan selalu memberikan kompensasi yang adil agar setiap karyawan merasakan kepuasan kerja dalam menjalankan pekerjaan mereka.

c. Hasil penelitian mengenai motivasi kerja terhadap kepuasan kerja di PT. Bank Sumut Cabang Sukaramai Medan mempunyai hasil yang relatif baik, sehingga disarankan agar pimpinan selalu memberikan dorongan motivasi yang lebih baik lagi agar karyawan merasakan kepuasan kerja yang tinggi dalam membantu perusahaan mencapai tujuantujuannya.

d. Hasil penelitian mengenai kompleksitas tugas terhadap motivasi kerja dan kepuasan kerja di PT. Bank Sumut Cabang Sukaramai Medan mempunyai hasil yang baik, sehingga disarankan selalu memperhatikan dalam memberikan tugas kepada para karyawan agar karyawan selalu termotivasi dalam menyelesaikan tugas mereka dan merasakan kepuasan kerja yang meningkat.

e. Bagi Penelitian Selanjutnya

Secara teori, Kompensasi dan Kompleksitas Tugas berpengaruh terhadap Kepuasan Kerja melalui Motivasi Kerja. Oleh karena itu direkomendasikan bagi peneliti selanjutnya untuk dapat mengembangkan hasil dari penelitian ini dengan menambahkan variabel lain seperti yang ingin dikembangkan dan menggunakan alat analisis yang lain untuk membuat penelitian tersebut bisa berkembang lagi untuk si peneliti selanjutnya.

\section{Daftar Pustaka}

Agung Kurniawan, K., Aju Brahmasari, I., \& Brahma Ratih, I. A. (2016). The Influence Of Organizational Culture, Task Complexity and, Competence On Job Satisfaction, Organizational Citizenship Behavior, and Nurse Performance Of Kodam VII / Wirabuana Sulawesi Indonesian National Army Hospital. International Journal of Business and Management Invention, 5(1), 1-11.

Ahmadi, C., \& Hermawan, D. (2013). E-Business dan E-Commerce. Yogyakarta: Andi Offset.

Atika, S. P., \& Prasetio, A. P. (2015). Pengaruh Kompensasi Terhadap Motivasi Kerja Karyawan PT. Mustika Ratu Cabang Bandung. Jurnal Universitas Langlang Buana, 134-154.

Bara Kusuma, Y., Swasto S, B., \& Al Musadieq, M. (2015). Pengaruh Kompensasi Terhadap Motivasi Kerja, Kepuasan Kerja, Dan Kinerja Karyawan (Studi pada Karyawan Tetap PT. Otsuka Indonesia di Lawang, Malang). Profit, 09(01), 43-56. https://doi.org/10.21776/ub.profit.2015.009.01.5

Kartika, E. W., Kaihatu, T. S., Perhotelan, P. M., Ekonomi, F., \& Petra, U. K. (2010). Analisis Pengaruh Motivasi Kerja Terhadap Kepuasan Kerja (Studi Kasus pada Karyawan Restoran di Pakuwon Food Festival Surabaya). Jurnal Manajemen Dan Kewirausahaan (Journal of Management and Entrepreneurship), 12(1), 100-112. https://doi.org/10.9744/jmk.12.1.pp.100-112 
Mangkunegara. (2011). Manajemen Sumber Daya Perusahaan. In Manajemen Sumber Daya Perusahaan.

Nurcahyani, N. M., \& Adnyani, I. G. A. D. (2016). Pengaruh Kompensasi Terhadap Kinerja Karyawan Dengan Motivasi Sebagai Variabel Intervening. E-Jurnal Manajemen Universitas Udayana, 5(1), 500-532. https://doi.org/10.31937/akuntansi.v4i2.131

Paulus, S., Hasan, A., \& Mezal, V. A. (2015). Pengaruh Gaya Kepemimpinan Terhadap Kepuasan Kerja Auditor Dengan Kompleksitas Tugas Dan Locus of Control Sebagai Variabel Moderating (Studi Survei Pada Kap Di Pekanbaru Dan Padang). Jurnal Online Mahasiswa Fakultas Ekonomi Universitas Riau, 2(1), 1-15.

Prassetiawan, A., \& Triyani, D. (2019). Pengaruh Motivasi, Kompensasi Dan Lingkungan Kerja Terhadap Kepuasan Kerja Karyawan (Studi Pada CV Enggal Jaya Semarang). Solusi, 16(4), 43-58. https://doi.org/10.26623/slsi.v16i4.1667

Sari, A. P., \& Ardana, K. (2016). Peran Mediasi Kepuasan Kerja Pada Pengaruh Kompensasi Terhadap Kinerja Pekerja Kontrak. E-Jurnal Manajemen Universitas Udayana, 5(1), 470499.

Wangsa, R. C. (2016). Pengaruh Kompensasi Dan Motivasi Kerja Terhadap Kepuasan Kerja Karyawan Serta Dampaknya Pada Kinerja Karyawan (Studi Kasus Pada PT. Daun Kencana Sakti). Agora, 4(1), 710-719. Retrieved from http://publication.petra.ac.id/index.php/manajemenbisnis/article/viewFile/6715/6085

Widodo, S. E. (2015). Manajemen Pengembangan Sumberdaya Manusia (Cetakan Ke). Yogyakarta: Pustaka Pelajar.

Yuniarsih, T., \& Suwatno. (2016). Manajemen Sumber Daya Manusia: Teori, Aplikasi, dan Isu Penelitian (Cetakan Ke). Bandung: Alfabeta.

Zulkarnaen, W., \& Kusmayadi, T. (2013). Pengaruh Kompleksitas Tugas, Orientasi Tujuan dan Efikasi Diri Terhadap Motivasi Kerja Pimpinan Bank Bri Se-Kota Bandung. 82-99. 
